\title{
DNA-Free Genetically Edited Grapevine and Apple Protoplast Using CRISPR/Cas9 Ribonucleoproteins
}

\begin{abstract}
Mickael Malnoy ${ }^{1 *}$, Roberto Viola1 ${ }^{\text {, Min-Hee Jung }}{ }^{2}$, Ok-Jae Koo ${ }^{2}$, Seokjoong Kim², Jin-Soo Kim ${ }^{3,4}$, Riccardo Velasco ${ }^{1}$ and Chidananda Nagamangala Kanchiswamy ${ }^{1 *}$

${ }^{1}$ Research and Innovation Centre, Genomics and Biology of Fruit Crop Department, Fondazione Edmund Mach, Trento, Italy, ${ }^{2}$ ToolGen Inc., Seoul, Republic of Korea, ${ }^{3}$ Center for Genome Engineering, Institute for Basic Science, Seoul, Republic of Korea, ${ }^{4}$ Department of Chemistry, Seoul National University, Seoul, Republic of Korea
\end{abstract}

OPEN ACCESS

Edited by:

Fabio Marroni,

University of Udine, Italy

Reviewed by:

Attila Molnar,

University of Edinburgh, UK Thorben Sprink,

Julius Kühn-Institut, Germany

Luisa Bortesi,

RWTH-Aachen University, Germany

${ }^{*}$ Correspondence:

Mickael Malnoy

mickael.malnoy@fmach.it

Chidananda Nagamangala

Kanchiswamy

chidananda.nagamangala@fmach.it

Specialty section:

This article was submitted to Technical Advances in Plant Science,

a section of the journal

Frontiers in Plant Science

Received: 11 September 2016 Accepted: 01 December 2016 Published: 20 December 2016

Citation:

Malnoy $M$, Viola $R$, Jung $M-H$, Koo O-J, Kim S, Kim J-S, Velasco $R$ and Nagamangala Kanchiswamy $C$ (2016) DNA-Free Genetically Edited

Grapevine and Apple Protoplast Using CRISPR/Cas9

Ribonucleoproteins.

Front. Plant Sci. 7:1904.

doi: 10.3389/fpls.2016.01904
The combined availability of whole genome sequences and genome editing tools is set to revolutionize the field of fruit biotechnology by enabling the introduction of targeted genetic changes with unprecedented control and accuracy, both to explore emergent phenotypes and to introduce new functionalities. Although plasmid-mediated delivery of genome editing components to plant cells is very efficient, it also presents some drawbacks, such as possible random integration of plasmid sequences in the host genome. Additionally, it may well be intercepted by current process-based GMO regulations, complicating the path to commercialization of improved varieties. Here, we explore direct delivery of purified CRISPR/Cas9 ribonucleoproteins (RNPs) to the protoplast of grape cultivar Chardonnay and apple cultivar such as Golden delicious fruit crop plants for efficient targeted mutagenesis. We targeted MLO-7, a susceptible gene in order to increase resistance to powdery mildew in grape cultivar and DIPM-1, DIPM2, and DIPM-4 in the apple to increase resistance to fire blight disease. Furthermore, efficient protoplast transformation, the molar ratio of Cas9 and sgRNAs were optimized for each grape and apple cultivar. The targeted mutagenesis insertion and deletion rate was analyzed using targeted deep sequencing. Our results demonstrate that direct delivery of CRISPR/Cas9 RNPs to the protoplast system enables targeted gene editing and paves the way to the generation of DNA-free genome edited grapevine and apple plants.

Keywords: genome editing, non-GMO, DNA-free, CRISPR/Cas9, apple, grapevine

\section{INTRODUCTION}

Grape and apple fruit crop plants are a major source of fiber, nutrients, and antioxidants, all essential for a healthy diet. These crops play a key role in the economy of many developed and developing countries and considerable efforts are being made to improve commercial traits using both conventional breeding and genetic engineering. However, growing social distrust in genetically modified (GM) crops in many countries has resulted in the adoption of very stringent and costly regulations disciplining the authorization of these crops, with the result that they have become very difficult or impossible to commercialize successfully (Sprink et al., 2016). Although genetic transformation of grape and apple crops has been used for the past two decades to enhance primarily biotic and abiotic tolerance, there are only a few examples of 
field evaluation or commercialization of transgenic plants worldwide (Kanchiswamy et al., 2015). A transition is needed toward more efficient and productive use of available genome sequences to meet growing demands for sustainable and safe intensification of food production. Here we explore the possibility of adopting next-generation plasmid-independent CRISPR/Cas9 genome editing approaches to develop improved grape and apple varieties that will probably avoid current GM regulations, and thus broaden the utility of this technology, with greater global acceptance levels. US Department of Agriculture (USDA) does not impose any GMO regulations to the plants with targeted mutagenesis generated by self-repair mechanisms, if they are free from Agrobacterium or any transgenic or foreign genetic materials; consequently, we assume there is high probability that CRISPR/Cas9 RNPs could be exempted from current GMO regulations (Waltz, 2012; Ledford, 2013; Jones, 2015). Nevertheless, the EU is uncertain to approve them and has yet to provide information on whether targeted mutation made by CRISPR/Cas9 or CRISPR/Cas9 RNPs fall outside regulatory criteria (Waltz, 2012; Jones, 2015).

CRISPR/Cas9 editing tools are efficiently exploited for gene mutation, repression, activation and epigenome editing in several model and crop plants, such as Arabidopsis, tobacco, rice, sorghum, maize, wheat, poplar, tomato, soya bean, petunia, citrus and recently grape and apple (Nishitani et al., 2016; Ren et al., 2016; Song et al., 2016). Meanwhile CRISPR/Cas9 RNPs DNA-free genome editing tools are successfully demonstrated in Arabidopsis, tobacco, lettuce, rice, petunia, and recently in wheat (Woo et al., 2015; Subburaj et al., 2016; Zhang et al., 2016).

To date, CRISPR/Cas9 RNPs editing tools have not been applied to genetic modification of grape and apple crops. Here, we demonstrate adoption of next-generation CRISPR/Cas9 RNPs technology for these fruit species to establish an efficient DNAfree method for the site-directed mutagenesis system. In the grapevine, PM (Gadoury et al., 2012; Pessina et al., 2016) is caused by the destructive fungal pathogen Erysiphe necator, an obligate biotroph infecting all green tissues and berries, resulting in drastic losses in yield and berry quality. Currently PM can be effectively controlled by frequent applications of fungicides in the field. However, the rapid emergence of new fungal strains and the hazardous effect of fungicides on the environment, combined with additional costs to growers (which can reach up to $20 \%$ of total production costs), demand the development of sustainable alternative strategies. Recently, it has been demonstrated that RNAi-mediated silencing of the susceptible gene (S-gene) MLO-7 significantly increases resistance to PM in the grapevine (Pessina et al., 2016). Here we targeted MLO-7 for mutagenesis in order to increase resistance to PM in commercially important cultivar such as Chardonnay.

The enterobacterial phytopathogen Erwinia amylovora causes fire blight, an invasive disease that threatens the apple and a wide range of commercial and ornamental Rosaceae host plants. Although, many studies have identified candidate genes as suitable targets for increasing fire blight resistance via genetic engineering, currently no resistant cultivars are commercially available, due to the social and regulatory hurdles associated with GMO plants (Singh et al., 2006). Here we selected important fruit producing apple cultivar Golden delicious to target DIPM1, DIPM-2, and DIPM-4, in order to increase resistance to fire blight disease (Meng et al., 2006). DIPM sequence structures are closely aligned with leucine-rich repeat receptor-like kinase receptors from several organisms, and furthermore DIPMs show direct physical interaction with the disease-specific (dsp) gene of Erwinia amylovora, which may act as a susceptible factor. Mutagenesis of DIPM-1,2, and 4 could provide apple cultivars resistant to fire blight disease.

We successfully show direct delivery of CRISPR/Cas9 RNPs to the grape and apple protoplast and efficient mutation of the targeted candidate genes. Targeted gene mutation, such as indel (insertion or deletion), was observed in 2 out of 2 specific sites of $M L O-7$ in grapevine cultivars and single specific sites of each DIPM-1, 2, and 4 in apple cultivars.

\section{MATERIALS AND METHODS}

\section{Grapevine Protoplast Preparation}

Grapevine protoplast was isolated from 15 to 20 days old embryogenic calli and 15-20 days old in vitro micro propagated young and healthy leaves. Embryogenic calli or young and healthy leaves (10-15) were used for protoplast isolation and transformation. These plant materials were immersed in cellwall digestion enzyme solution mix containing macerozyme R-10 (0.1-0.5\%) and cellulase R-10 (1-2\%) in $20 \mathrm{mM}$ MES, $0.5 \mathrm{M}$ mannitol, $20 \mathrm{mM} \mathrm{KCL}$, and $10 \mathrm{mM} \mathrm{CaCl}_{2}$. Vacuum infiltration of plant materials took place with cell-wall digestion enzyme for 20 mins before incubating them at room temperature in a rotary shaker at $40 \mathrm{rpm}$ for $4 \mathrm{~h}$ (embryogenic calli) or overnight (leaves). After digestion, protoplasts were filtered through Nylon mesh $(75 \mu \mathrm{M})$, with the addition of 1:1 protoplast enzyme solution and W5 washing solution (5 mM glucose, $2 \mathrm{mM}$ MES ( $\mathrm{pH}$ 5.7), $154 \mathrm{mM} \mathrm{NaCl}, 125 \mathrm{mM} \mathrm{CaCl}_{2}$, and $5 \mathrm{mM} \mathrm{KCl}$ ), harvesting the protoplast by centrifugation at $100 \times g$ for 5 mins. The supernatant was discarded and the protoplast re-suspended in $5 \mathrm{ml}$ of W5 solution. A wide mouthed or point cut pipette tip was used to slowly transfer the protoplast to $5 \mathrm{ml}$ of sucrose solution $(21 \%)$, then centrifuged at $50 \times g$ for 5 mins. A Pasteur pipette was used to suck the interface protoplast layer (viable and healthy protoplast), then re-suspended in $25 \mathrm{ml}$ of W5 solution and incubated at $4^{\circ} \mathrm{C}$ for $1 \mathrm{~h}$. This was centrifuged at $50 \times g$ for $5 \mathrm{mins}$, the supernatant discarded and the protoplasts resuspended in MMG solution (0.5 M mannitol, 4 mM MES ( $\mathrm{pH}$ 5.7) and $15 \mathrm{mM} \mathrm{MgCl}_{2}$ ). The protoplast was counted using a hemocytometer and $2 \times 10^{5}$ cells used for each CRISPR RNPs transformation. At least two biological replications and three technical replication sets were used to optimize and measure enzyme concentration and protoplast yield.

\section{Apple Protoplast Preparation}

Apple protoplast was isolated from 20 to 25 days old in vitro micro propagated young and healthy leaves (10-15). The protocol for apple protoplast preparation was similar to that for the grapevine, except for the addition of hemicellulase to the cell-wall digestion enzyme solution (1-2\%). The viability and 
density of grape and apple protoplast were determined using a haemocytometer, by staining the protoplast with fluorescein diactetate (FDA) as described elsewhere (Lei et al., 2015). At least two biological replications and three technical replication sets were used to optimize and measure enzyme concentration and protoplast yield.

\section{In vitro sgRNA Cleavage Assay}

Commercially available ready to use recombinant Cas9 protein $(160 \mathrm{kDa})$ and $\mathrm{sgRNAs}$ were purchased from ToolGen, Inc. (Seoul, Republic of Korea). The sgRNAs were designed for target-specific sites which have higher out-of-frame scores, to achieve maximum knock out efficiency in the MLO-7 coding regions of the grapevine and the DIPM1, DIPM 2 and 4 of the apple and highly efficient sgRNAs are selected via CRISPR RGEN Tools website ${ }^{1}$ (Bae et al., 2014; Figure 1; Table 1). For assessment of activity of CRISPR/Cas9 system, in vitro cleavage assay was performed as described elsewhere (Cho et al., 2013). Corresponding target sites were amplified by specific primer sets (Table 2), amplified PCR product (300 ng) is incubated for $60 \mathrm{~min}$ at $37^{\circ} \mathrm{C}$ with Cas 9 protein $(25 \mathrm{nM})$ and sgRNA $(25 \mathrm{nM})$ in $10 \mu \mathrm{l}$ NEB 3 buffer $(1 \times)$. Reactions were stopped with $6 \times$ stop solution containing $30 \%$ glycerol, $1.2 \%$ SDS, and 100 mM EDTA. Products were resolved with $1 \%$ agarose gel electrophoresis and visualized with EtBr staining (Figure 3). Purified recombinant Cas9 protein and sgRNA were used in a ratio of $1: 3,3: 1$, and $1: 1$ (in $\mu$ ) to optimize the highest mutation efficiency during protoplast transformation. We used same amount of Cas9 protein for 1:3

${ }^{1}$ http://rgenome.net/ and 1:1 conditions and three times more Cas9 protein for 3:1 condition.

\section{Protoplast Transformation with CRISPR RNPs}

In order to optimize efficient targeted mutagenesis of grapevine $M L O-7$ and the DIPM-1, 2, and 4 of apple gene loci, $2 \times 10^{5}$ re-suspended protoplasts were transformed with Cas9 protein and sgRNA in a ratio of 1:3, 3:1, and 1:1 (Woo et al., 2015; Subburaj et al., 2016). Protoplast volume $200 \mu \mathrm{l}\left(2 \times 10^{5}\right.$ cells $)$ and RNPs for example 3:1 is Cas9 $90 \mu \mathrm{g}$ (stock $10 \mu \mathrm{g} / \mu \mathrm{l}$ ) sgRNA $30 \mu \mathrm{g}$ (stock $10 \mu \mathrm{g} / \mu \mathrm{l}$ ) is used for transformation. Prior to the transformation, Cas 9 and sgRNA were pre-mixed and incubated at room temperature for 10 mins. The protoplast, Cas9 and sgRNA mix were mixed and an equal volume of PEG 4000 added, gently but immediately mixing the tube before aggregation occurred and incubating it for 20 mins at room temperature. Four hundred microliter or an equal volume of W5 solution were added, mixed and incubated at room temperature for further 10 mins. An additional $800 \mu$ l were added or the volume of W5 solution doubled, mixed and incubated at room temperature for further 10 mins. This was centrifuged at $50 \times g$ for 5 mins, the supernatant discarded and $1 \mathrm{ml}$ of W5 solution added, followed by incubation at room temperature in the dark overnight. The lower sediments were collected for genomic DNA isolation. Three biological replications are performed for protoplast transformation and isolated genomic DNA from protoplast transfected cells are further used for targeted deep sequencing.

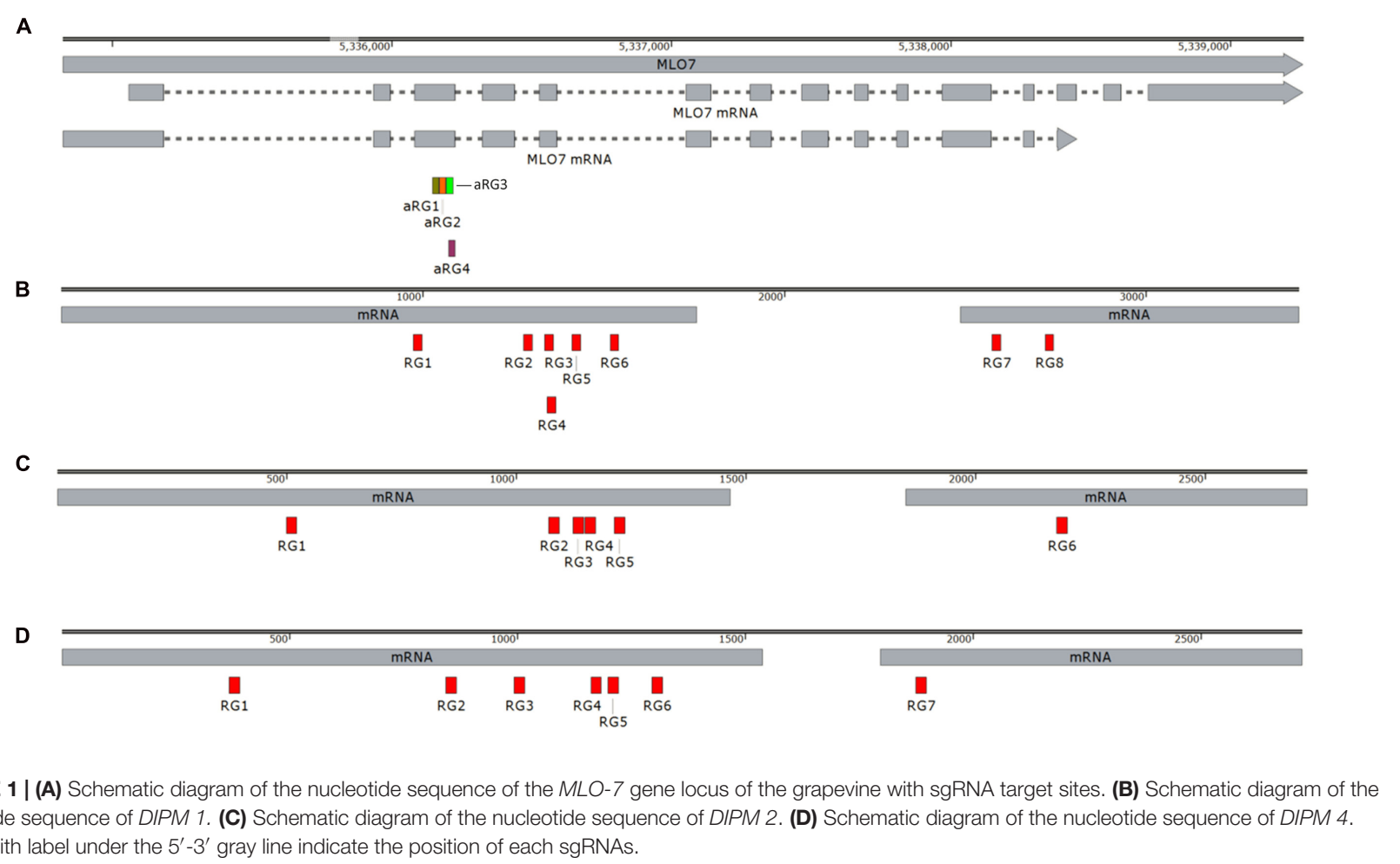

nucleotide sequence of DIPM 1. (C) Schematic diagram of the nucleotide sequence of DIPM 2. (D) Schematic diagram of the nucleotide sequence of DIPM 4. Boxes with label under the $5^{\prime}-3^{\prime}$ gray line indicate the position of each sgRNAs. 
TABLE 1 | List of sgRNAs designed to target grape MLO-7 gene locus and apple DIPM-1, 2, and 4 gene loci.

\begin{tabular}{|c|c|c|}
\hline Target & sgRNA & Sequence $\left(5^{\prime}-3^{\prime}\right)$ \\
\hline \multirow[t]{4}{*}{ MLO-7 } & $R \mathrm{R}_{1}$ & TATGCATTCTGAGAGTGTTGGG \\
\hline & RG2 & САCTTGGCACCCTTGTAAAAAGG \\
\hline & RG3 & CCAAAGATITAAGAACACATGC \\
\hline & RG4 & TTTTAAGAACACATGCTCTGAGG \\
\hline \multirow[t]{8}{*}{ DIPM-1 } & $R \mathrm{R}_{1}$ & CGTCGTTCAGCTCAACCCGGGG \\
\hline & RG2 & CGATTGGCTGGTGAGGTAATTGG \\
\hline & RG3 & AAGCACAGATCCCAGAACGGAGG \\
\hline & $\mathrm{RG} 4$ & GATCCCAGAACGGAGGGAGGTGG \\
\hline & RG5 & CGAGAGCAATTCCAAGGAGCGGG \\
\hline & RG6 & TAGCATTGGGACTACGTACAAGG \\
\hline & $\mathrm{RG} 7$ & CATGGATGAGGGACGACGATIGG \\
\hline & RG8 & TACTGGACTTGCGAATCTCGGGG \\
\hline \multirow[t]{6}{*}{ DIPM-2 } & $R G 1$ & ACGGAAGAGAGAGGTTGCGGAGG \\
\hline & RG2 & CAGTTCTAGAAGCTTCGAGCGG \\
\hline & RG3 & CTCGTACCCGGGTTGGGCAGAGG \\
\hline & RG4 & GGTCGGATGGTGTTCTTCGAAGG \\
\hline & RG5 & CCCGCCTTCCCCAGCATCTCGG \\
\hline & RG6 & CACGGGGAAGTGTCCCTCCGTGG \\
\hline \multirow[t]{7}{*}{ DIPM-4 } & RG1 & AGCGACTACGCGGTCTIATIGG \\
\hline & RG2 & GAACAAGCCGGCAAGGGGCTCGG \\
\hline & RG3 & ACGATCGCAACGATTGCGCCGGG \\
\hline & RG4 & AAGGTGTACGCGAACAGCGGGGG \\
\hline & RG5 & ACGGTACAAACGCGACGGACAGG \\
\hline & RG6 & GGGGAAAGGAAGCCTAGGGACGG \\
\hline & RG7 & GCTGTATTCCGCATGAATCCTGG \\
\hline
\end{tabular}

Sequences of sgRNA in bold indicate selected sgRNAs used in the study for transformation. Underlined nucleotides indicate PAM motifs in sgRNA sequences.

\section{Targeted Deep Sequencing}

Sequence at the sgRNA target sites were analyzed as described elsewhere (Woo et al., 2015). Corresponding target sites were PCR amplified using the primers listed in Table 2. Amplifications were performed using Phusion polymerase. Amplified PCR products were sequenced using the Illumina MiSeq platform (Quail et al., 2012). Mutations induced by CRISPR RNPs were calculated based on the indels around the CRISPR RNPs cleavage sites ( 3 bp upstream of PAM) using CRISPR RGEN Tools software ${ }^{2}$. Three biological replications are performed for targeted deep sequencing. Average of three biological replications are used for statistical analysis to determine percentage of indel ratio.

\section{RESULTS}

\section{Protoplast Isolation in Grapevine and Apple Cultivar}

In the grapevine, embryogenic calli provided a higher yield of up to $3.6 \times 10^{6}$ with $90 \%$ viability when using $1.5 \%$ cellulase R-10 and $0.4 \%$ macerozyme R-10, with 20 min of vacuum infiltration followed by $3 \mathrm{~h}$ incubation with gentle shaking

${ }^{2}$ http://rgenome.net/
TABLE 2 | List of primers used for in vitro cleavage assay and targeted deep sequencing.

\begin{tabular}{|c|c|}
\hline Target & Sequence $\left(5^{\prime}-3^{\prime}\right)$ \\
\hline $\begin{array}{l}\text { MLO- } 7 \text { in vitro } \\
\text { cleavage assay }\end{array}$ & $\begin{array}{l}\text { F; GCAGTGGTTAAAAGGCAGAC } \\
\text { R; CTTGGTTCTTCCCAAAGCC }\end{array}$ \\
\hline $\begin{array}{l}\text { MLO-7 deep } \\
\text { sequencing }\end{array}$ & $\begin{array}{l}\text { F; CCAAAGGTCTAACCCTITC } \\
\text { R; GGGAAACACCTIITCAGTC }\end{array}$ \\
\hline $\begin{array}{l}\text { DIPM-1 in vitro } \\
\text { cleavage assay }\end{array}$ & $\begin{array}{l}\text { For RG1 - RG6 } \\
\text { F; TITAATCTTCAACGTCTCC } \\
\text { R; TTGCCTGAAAATAAGCCCTC } \\
\text { For RG7 and RG8 } \\
\text { F; TAGTAACCAAAGGGAAGTGG } \\
\text { R; TTCAACACTTGCCACATTGC }\end{array}$ \\
\hline $\begin{array}{l}\text { DIPM-1 deep } \\
\text { sequencing }\end{array}$ & $\begin{array}{l}\text { F; GTCTTATGCCTCTITGCGG } \\
\text { R; CTCCAGACTGTATAGCTGAG }\end{array}$ \\
\hline \multirow[t]{3}{*}{$\begin{array}{l}\text { DIPM-2 in vitro } \\
\text { cleavage assay }\end{array}$} & $\begin{array}{l}\text { For RG1 } \\
\text { F; TGCACAAATAACCGAGTCTC } \\
\text { R; ACTATGATGGCGATTAGAGC }\end{array}$ \\
\hline & $\begin{array}{l}\text { For RG2 to RG5 } \\
\text { F; CAAGGGTACATCAAACGACC } \\
\text { R; AAATTACCGTGGAGAACCC }\end{array}$ \\
\hline & $\begin{array}{l}\text { For RG6 } \\
\text { F; ACATCCTCTTAGACAAGACC } \\
\text { R; AGCACAAACGAAAACGAGAG }\end{array}$ \\
\hline $\begin{array}{l}\text { DIPM-2 deep } \\
\text { sequencing }\end{array}$ & $\begin{array}{l}\text { F; CGCTGCTCCTGTACTGCTAC } \\
\text { R; GTCGAGCACCGCCTTGTA }\end{array}$ \\
\hline \multirow[t]{3}{*}{$\begin{array}{l}\text { DIPM-4 in vitro } \\
\text { cleavage assay }\end{array}$} & $\begin{array}{l}\text { For RG1 } \\
\text { F; AGAAAAACAAGCCTITCGCG } \\
\text { R; TCCGTACAATTCGTTGTTGG }\end{array}$ \\
\hline & $\begin{array}{l}\text { For RG2 to RG6 } \\
\text { F; CACCAACAACGAATTGTACGG } \\
\text { R; AGTAATAAGCACTCAGCCTC }\end{array}$ \\
\hline & $\begin{array}{l}\text { For RG7 } \\
\text { F; TGCAGTTGGATCTAATGCG } \\
\text { R; CCTCAATGTCTTGTACCTC }\end{array}$ \\
\hline $\begin{array}{l}\text { DIPM-4 deep } \\
\text { sequencing }\end{array}$ & $\begin{array}{l}\text { F; GATGTAATTAAGGGAATCGG } \\
\text { R; CAATCTTGCAATGGCGTGAA }\end{array}$ \\
\hline
\end{tabular}

(Table 3). Conversely, leaves gave a lower protoplast yield and lower viability, with incubation periods of up to $24 \mathrm{~h}$. In the apple, cell wall digestion with $1.5 \%$ cellulase $\mathrm{R}-10,0.4 \%$ macerozyme $\mathrm{R}-10$, and $1 \%$ hemicellulase provided a maximum yield of $1.0 \times 10^{6}$ with $80 \%$ viability, with 20 min of vacuum infiltration followed by $24 \mathrm{~h}$ incubation with gentle shaking, compared to the other ranges of various cell wall digesting enzyme concentrations (Table 1). In the apple, we selected leaves and avoided callus explants, due to their hard structure and lower protoplast yield.

\section{Targeted Mutagenesis of the Grapevine and the Apple Using CRISPR/Cas9 RNPs}

To identify suitable sgRNAs for targeted mutagenesis, we designed several sgRNAs for each gene used in the present study and then cleavage frequencies of each sgRNAs were assessed using an in vitro digestion assay. All the sgRNAs used in this study were designed to pair with their corresponding 20 nucleotide target sites in MLO-7, DIPM-1, 2 and 4 gene loci and to assist Cas9 to create site-specific double strand breaks (DSBs) at $3 \mathrm{bp}$ upstream of the PAM motifs (Table 1). As shown in Figure 2, 
sgRNAs in each gene showing the highest cleavage rate were selected for further study. To target the grapevine MLO-7 gene locus, we used sgRNA RG4 (Figure 2). Similarly, in the apple we used three specific sgRNAs for the DIPM-1 (RG2), DIPM-2 (RG4), and DIPM-4 (RG7) loci (Figure 2), respectively.

\section{Targeted Deep Sequencing to Analyze the Mutation Efficiency of CRISPR/Cas9 RNPs}

In order to detect the mutation efficiency and mutation patterns at different sites in the grape gene locus MLO-7 and the apple gene loci DIPM-1, 2, and 4, we employed targeted deep sequencing of genomic DNA obtained from each protoplast pool during PCR amplification. Total genomic DNA was extracted from transformed protoplast, while CRISPR/Cas9 target sites in $M L O-7, D I P M-1,2$, and 4 were amplified using site-specific primers (Table 2). PCR amplified products were subjected to targeted deep sequencing. Targeted deep sequencing results showed that there were various number indel mutation frequencies (\%) for each CRISPR sgRNA sample (Table 4).

As shown in Table 4, various mutation patterns including indels were detected in all the different sgRNA RNPs complex transformed protoplast samples, whereas no mutations were detected in sgRNA-only or Cas9-only transformed protoplast samples. These results demonstrate direct delivery of CRISPR RNPs to grapevine and apple protoplast, and indel mutagenesis efficiency of $0.1 \%$ and 0.5 to $6.9 \%$ for targeted distinct sites of endogenous MLO-7 and DIPM-1, 2, and 4 via DSBs, respectively.

\section{DISCUSSION}

Plant protoplasts constitute a dynamic and versatile system for CRISPR/cas9 genome editing in plants and has been widely adopted in several crop species for functional analysis of the traits concerned, cellular localization, and studies of multiple signaling cascades (Shan et al., 2013; Xie and Yang, 2013; Zhao et al., 2016). CRISPR/Cas9 or other genome editing tools mediated protoplast transfection system has been successfully adopted in Arabidopsis, rice, wheat, maize, tobacco, lettuce, and petunia (Jiang et al., 2013; Li et al., 2013; Shan et al., 2013; Wang et al., 2014; Gao et al., 2015; Woo et al., 2015; Subburaj et al., 2016), however, a similar system has not been developed for the grapevine and apple. In this study, we isolated protoplast from embryogenic calli and leaves of grapevine and apple cultivar in order to standardize an efficient protocol for the transient expression system of CRISPR/Cas9 RNPs. Protoplast isolation, transfection and transient gene expression system in grape and apple has been little explored and most of the available methods have not been updated for two decades (Doughty and Power, 1988; Patat-Ochatt et al., 1993; Patat-Ochatt, 1994; Reustle et al., 1995; Zhu et al., 1997; Saito and Suzuki, 1999; Fontes et al., 2010). Protoplast viability, yield, and efficient transfection depend on various factors, such as the concentration of cell wall digestion enzymes, buffer conditions, the osmotic status of protoplasts, the incubation period, and the type of explants used for protoplast isolation. In the current study, all these variables were updated and optimized in order to achieve a better yield. This is the first report of successful demonstration of CRISPR/Cas9 RNPs mediated protoplast transformation in grapevine and apple cultivars. Our method for transient expression of genome editing tools in the protoplast to target the gene of interest with specificity and higher efficiency should help grapevine and apple scientists to analyze the traits concerned in the host plant within a day or two. Furthermore, future work on regeneration of genome edited protoplast will provide an opportunity to develop DNAfree genome edited grapevine and apple fruit crop plants. One such example is regeneration of apple plants from meristem derived callus protoplast (Saito and Suzuki, 1999).

CRISPR/Cas9 is easy to prepare, scalable and affordable compared to ZFNs and TALENs. However, the broader application of plasmid mediated CRISPR/Cas9 to life sciences, biotechnology and medicine is limited by off-target effects, unwanted integration of plasmid vectors into the genome and possible GMO regulations (Hendel et al., 2015; Zhang et al., 2015). In order to overcome these limitations, we delivered CRISPR/Cas9 RNPs rather than plasmids directly into the protoplast cells and showed that RNPs enable efficient genome editing, while avoiding unwanted integration of plasmid DNA in the host genome, similar to other recent studies done in human, animal and plant cells (Figure 3; Kim et al., 2014; Lee et al., 2014; Liu et al., 2015; Woo et al., 2015; Subburaj et al., 2016).

Recently several groups have demonstrated that CRISPR/Cas9 can induce unwanted mutations in off-target sites, differing from

TABLE 3 | Grape and apple protoplast yield with various concentrations of the cell-wall digestion enzymes from leaves (10-15 healthy leaves) and embryogenic calli (100 mg).

\begin{tabular}{|c|c|c|c|}
\hline Plant materials & Cultivar & Enzyme concentration & Protoplast yield \\
\hline \multicolumn{4}{|l|}{ Grapevine cultivar } \\
\hline Leaves & Chardonnay & Macerozyme R10-0.1\%, Cellulase R10-1\% & $2 \times 10^{6}$ protoplast per $\mathrm{ml}$ \\
\hline Leaves & Chardonnay & Macerozyme R10-0.15\%, Cellulase R10 - 1\% & $2 \times 10^{5}$ protoplast per $\mathrm{ml}$ \\
\hline Embryogenic calli & Chardonnay & Macerozyme R10-0.1\%, Cellulase R10-1\% & $4 \times 10^{6}$ protoplast per $\mathrm{ml}$ \\
\hline Embryogenic calli & Chardonnay & Macerozyme R10-0.15\%, Cellulase R10-1\% & $3 \times 10^{6}$ protoplast per $\mathrm{ml}$ \\
\hline \multicolumn{4}{|l|}{ Apple cultivar } \\
\hline Leaves & Golden delicious & Macerozyme R10-0.15\%, Cellulase R10-1\%, Hemicellulase-1\% & $1.8 \times 10^{6}$ protoplast per $\mathrm{ml}$ \\
\hline Leaves & Golden delicious & Macerozyme R10-0.15\%, Cellulase R10-1\%, Hemicellulase-1.5 \% & $1.0 \times 10^{6}$ protoplast per $\mathrm{ml}$ \\
\hline
\end{tabular}

At least two biological replications and three technical replication sets were used to optimize and measure enzyme concentration and protoplast yield. 


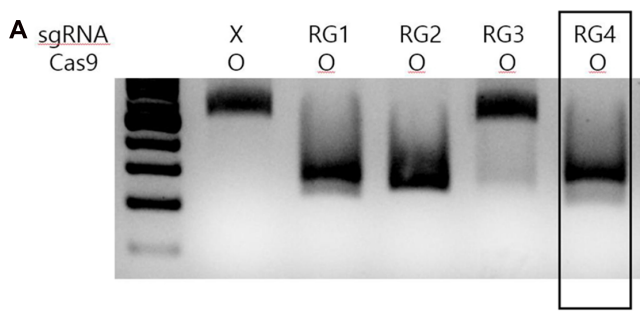

C

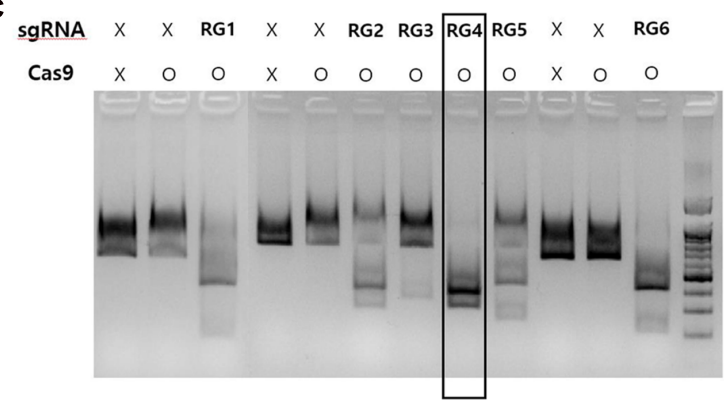

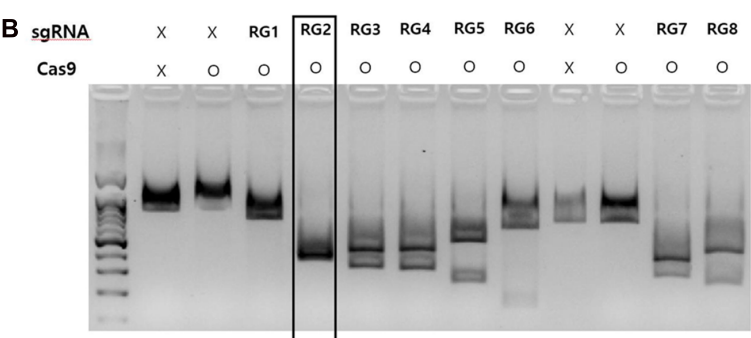

D

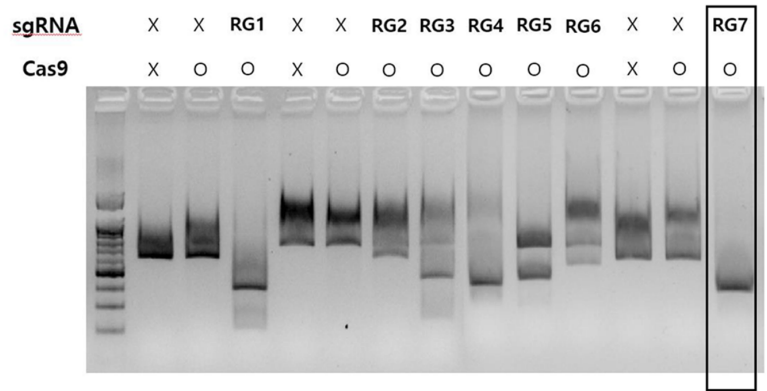

FIGURE 2 | CRISPR/Cas9 RNPs in vitro digestion assay results of each sgRNAs used in the study. (A) In vitro digestion of targeted loci at MLO-7 gene. (B) In vitro digestion of targeted locus in the DIPM-2 gene. (C) In vitro digestion of targeted locus in the DIPM-2 gene. (D) In vitro digestion of targeted locus in the DIPM-4 gene. In each group, non-treated (sgRNA: x; Cas9: $x$ ) or Cas9-only (sgRNA: x; Cas9: o) samples were used as a control. After treatment with Cas9 with targeted sgRNA (RG1 to RG8 in each group) amplified target genomic DNA was digested and smaller bands were detected in gels after electrophoresis. Groups showing an intense band after digestion (indicated with black boxes) were selected and used for further experiments.
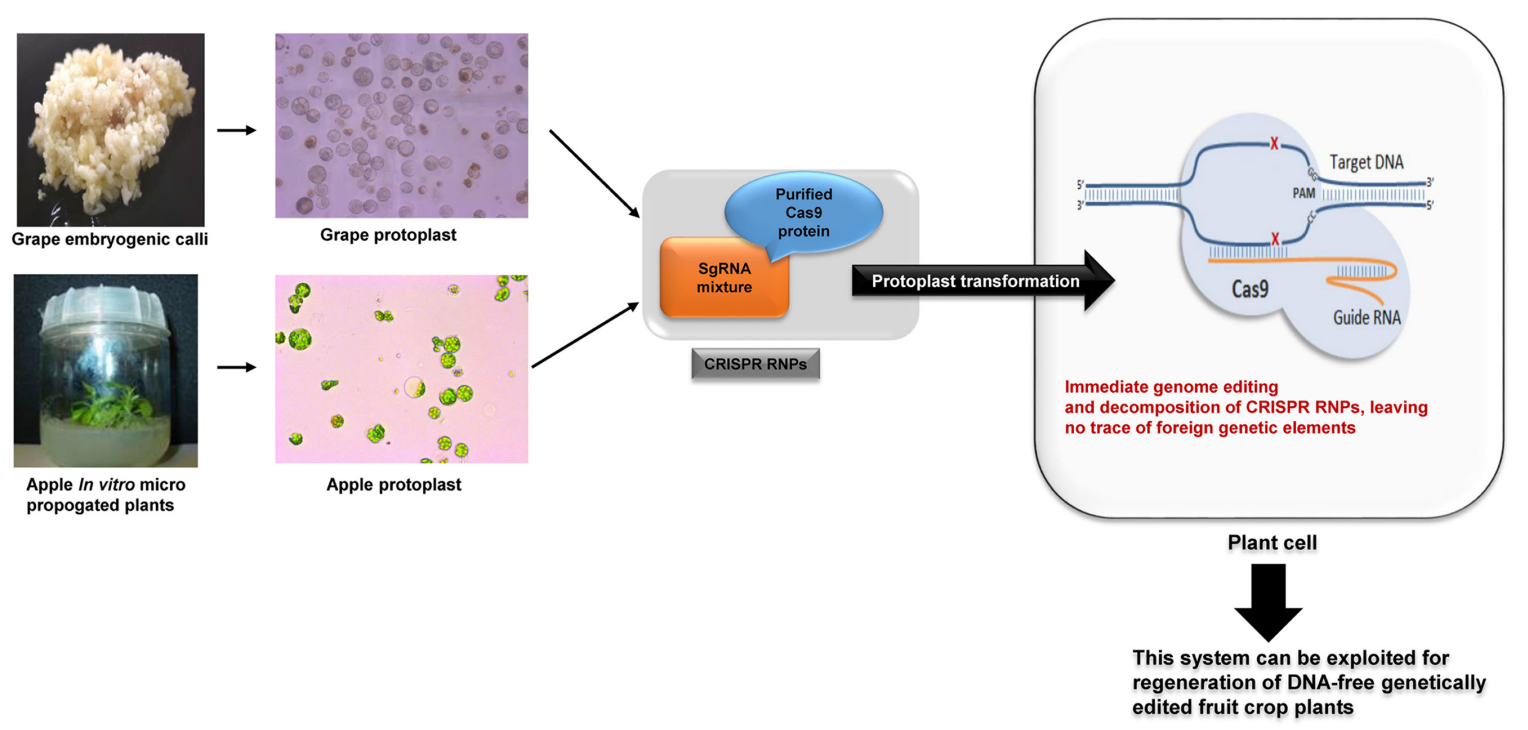

FIGURE 3 | Schematic diagram of CRISPR RNPs direct delivery to grape and apple plant cells to produce DNA-free genetically edited crop plants.

on-target sites by up to $5 \mathrm{nt}$, leading to questions about their specificity (Cradick et al., 2013; Fu et al., 2013; Hsu et al., 2013; Tan et al., 2015). We and others have proposed various strategies to improve the on-target specificity of CRISPR/Cas9 (Koo et al., 2015; Kanchiswamy et al., 2016). Synthesis of unique sgRNA (Cho et al., 2014; Fu et al., 2014; Sung et al., 2014), Cas9 nickases and web based computer programs to identify unique target sites (Mali et al., 2013; Ran et al., 2013; Bae et al., 2014) and CRISPR/Cas9 RNPs (Woo et al., 2015). In order to facilitate the highest site-specific mutation frequency in grape and apple protoplast, we titrated the ratio of Cas 9 and sgRNAs, in a similar way to our previous studies (Hsu et al., 2013; Woo et al., 2015). In this study, we employed three different Cas9: sgRNA ratios, i.e., $3: 1,1: 1$, and 1:3, for protoplast PEG mediated transformation 
TABLE 4 | Mutation rate assay by targeted deep sequencing in MLO-7, DIPM 1, 2, and 4.

\begin{tabular}{|c|c|c|c|c|c|c|c|c|c|c|c|}
\hline \multirow[t]{2}{*}{ Target gene } & \multirow[t]{2}{*}{ Sample name } & \multicolumn{3}{|c|}{$\begin{array}{l}\text { Number of Reads } \\
\text { (more than minimum } \\
\text { frequency) }\end{array}$} & \multicolumn{3}{|c|}{ Number of insertion mutations } & \multicolumn{3}{|c|}{ Number of deletion mutations } & \multirow[t]{2}{*}{$\begin{array}{c}\text { Indel ratio } \\
\text { (average, \%) }\end{array}$} \\
\hline & & 1 & 2 & 3 & 1 & 2 & 3 & 1 & 2 & 3 & \\
\hline \multirow[t]{5}{*}{ MLO-7 (RG4, grape) } & sgRNA only & 56302 & 52455 & 54565 & 0 & 0 & 0 & 0 & 0 & 0 & 0.00 \\
\hline & Cas9 only & 9924 & 10123 & 10001 & 0 & 0 & 0 & 0 & 0 & 0 & 0.00 \\
\hline & Cas9: sgRNA, 1:1 & 51558 & 52015 & 52206 & 0 & 0 & 0 & 49 & 55 & 64 & 0.10 \\
\hline & Cas9; sgRNA, 1:3 & 56546 & 55432 & 56421 & 2 & 4 & 6 & 71 & 74 & 69 & 0.10 \\
\hline & Cas9; sgRNA, 3:1 & 67286 & 64532 & 66876 & 42 & 57 & 68 & 10 & 12 & 9 & 0.10 \\
\hline \multirow[t]{5}{*}{ DIPM1 (RG2, apple) } & sgRNA only & 58020 & 57987 & 58911 & 0 & 0 & 0 & 2 & 0 & 1 & 0.00 \\
\hline & Cas9 only & 53727 & 54455 & 55432 & 0 & 0 & 0 & 5 & 7 & 8 & 0.00 \\
\hline & Cas9: sgRNA, 1:1 & 60903 & 60467 & 60787 & 0 & 0 & 0 & 16 & 22 & 13 & 0.00 \\
\hline & Cas9; sgRNA, 1:3 & 65674 & 64678 & 65632 & 0 & 0 & 0 & 15 & 19 & 22 & 0.00 \\
\hline & Cas9; sgRNA, 3:1 & 61565 & 62639 & 60166 & 0 & 0 & 0 & 4150 & 4500 & 3989 & 6.70 \\
\hline \multirow[t]{5}{*}{ DIPM2 (RG4, apple) } & sgRNA only & 22397 & 22565 & 22001 & 0 & 0 & 0 & 0 & 0 & 0 & 0.00 \\
\hline & Cas9 only & 16021 & 17089 & 17345 & 0 & 0 & 0 & 0 & 0 & 0 & 0.00 \\
\hline & Cas9: sgRNA, 1:1 & 17847 & 18945 & 17923 & 447 & 565 & 472 & 140 & 167 & 178 & 3.30 \\
\hline & Cas9; sgRNA, 1:3 & 17965 & 17456 & 17989 & 80 & 74 & 92 & 2 & 4 & 5 & 0.50 \\
\hline & Cas9; sgRNA, 3:1 & 17005 & 17233 & 17565 & 291 & 300 & 267 & 271 & 288 & 298 & 3.30 \\
\hline \multirow[t]{5}{*}{ DIPM4 (RG7, apple) } & sgRNA only & 20239 & 20679 & 20899 & 0 & 0 & 0 & 0 & 0 & 0 & 0.00 \\
\hline & Cas9 only & 32096 & 32198 & 32345 & 0 & 0 & 0 & 0 & 0 & 0 & 0.00 \\
\hline & Cas9: sgRNA, 1:1 & 42871 & 43211 & 43001 & 691 & 701 & 719 & 2253 & 2300 & 2310 & 6.90 \\
\hline & Cas9; sgRNA, 1:3 & 22055 & 22100 & 22189 & 0 & 0 & 0 & 555 & 567 & 590 & 2.50 \\
\hline & Cas9; sgRNA, 3:1 & 30240 & 31000 & 30319 & 0 & 0 & 0 & 1835 & 2000 & 2187 & 6.10 \\
\hline
\end{tabular}

in the grape and the apple. We determined that the 3:1 ratio for MLO-7 in the grapevine, the 3:1 ratio for DIPM 1, the 1:1 and 3:1 ratio for DIPM 2 and the 1:1 ratio for DIPM 4 in the apple resulted in highest mutation frequency. Here, we showed the critical advantage over plasmid mediated genome editing delivery by titrating the Cas9:sgRNA ratio to achieve maximum mutation frequency (Liu et al., 2015; Kanchiswamy et al., 2016).

This study demonstrated direct delivery of CRISPR/Cas9 RNPs to grape and apple protoplasts and site-directed mutation of the grape gene locus $M L O-7$ and the apple gene loci DIPM-1, 2 , and 4 .

\section{CONCLUSION}

We demonstrated efficient targeted mutagenesis in the grapevine gene locus $M L O-7$ and the apple gene loci DIPM-1, 2, and 4, using direct delivery of CRISPR RNPs. Although the mutation efficiency was found to vary with the targeted gene locus and the ratio of Cas9 and sgRNA, mutation patterns and frequency assays showed CRISPR RNPs to be an effective strategy for targeted mutagenesis of gene loci in grape and apple protoplasts. This method has already shown improved features compared to plasmid-mediated genome editing in humans, animals and plants, such as higher efficiency, significantly reduced off-target effects and more rapid editing activity after delivery (Liu et al., 2015; Woo et al., 2015; Kanchiswamy, 2016; Kanchiswamy et al., 2016). Furthermore, in plants, the new varieties obtained with this approach may be deregulated from current GMO legislations, as the Cas9 protein-guide RNA complexes will rapidly decompose in regenerating cell cultures. Further studies are now required to optimize plant regeneration from CRISPR RNPs transformed protoplast to explore the applications of this technology at field level.

\section{AUTHOR CONTRIBUTIONS}

$\mathrm{CN}, \mathrm{O}-\mathrm{JK}$, and $\mathrm{M}-\mathrm{HJ}$ performed and designed experiments. RV, SK, J-SK, RiV, and MM provided materials, funding, plan for the experiment. $\mathrm{CN}$ wrote manuscript with the cooperation and support of all co-authors.

\section{FUNDING}

This work was supported by the research funding office of the Autonomous Province of Trento.

\section{ACKNOWLEDGMENTS}

We would like to thank Stefano Piazzo, Valentino Poletti, and Lorenza Dallacosta from the Research and Innovation Centre, in the Genomics and Biology of Fruit Crop Department, Fondazione Edmund Mach, Trento, Italy for providing plant materials. 


\section{REFERENCES}

Bae, S., Park, J., and Kim, J. S. (2014). Cas-OFFinder: a fast and versatile algorithm that searches for potential off-target sites of Cas9 RNA-guided endonucleases. Bioinformatics 30, 1473-1475. doi: 10.1093/bioinformatics/btu048

Cho, S. W., Kim, S., Kim, J. M., and Kim, J. S. (2013). Targeted genome engineering in human cells with the Cas9 RNA-guided endonuclease. Nat. Biotechnol. 31, 230-232. doi: 10.1038/nbt.2507

Cho, S. W., Kim, S., Kim, Y., Kweon, J., Kim, H. S., Bae, S., et al. (2014). Analysis of off-target effects of CRISPR/Cas-derived RNA-guided endonucleases and nickases. Genome Res. 24, 132-141. doi: 10.1101/gr.162339.113

Cradick, T. J., Fine, E. J., Antico, C. J., and Bao, G. (2013). CRISPR/Cas9 systems targeting beta-globin and CCR5 genes have substantial off-target activity. Nucleic Acids Res. 41, 9584-9592. doi: 10.1093/nar/gkt714

Doughty, S., and Power, J. B. (1988). Callus formation from leaf mesophyll protoplasts of Malus Xdomestica Borkh. cv. Greensleeves. Plant cell Rep. 7, 200-201. doi: 10.1007/BF00269323

Fontes, N., Delrot, S., and Geros, H. (2010). A method for the isolation of protoplasts from grape berry mesocarp tissue. Recent Pat. Biotechnol. 4, 125-129. doi: 10.2174/187220810791110705

Fu, Y., Foden, J. A., Khayter, C., Maeder, M. L., Reyon, D., Joung, J. K., et al. (2013). High-frequency off-target mutagenesis induced by CRISPR-Cas nucleases in human cells. Nat. Biotechnol. 31, 822-826. doi: 10.1038/nbt.2623

Fu, Y., Sander, J. D., Reyon, D., Cascio, V. M., and Joung, J. K. (2014). Improving CRISPR-Cas nuclease specificity using truncated guide RNAs. Nat. Biotechnol. 32, 279-284. doi: $10.1038 /$ nbt.2808

Gadoury, D. M., Cadle-Davidson, L., Wilcox, W. F., Dry, I. B., Seem, R. C., and Milgroom, M. G. (2012). Grapevine powdery mildew (Erysiphe necator): a fascinating system for the study of the biology, ecology and epidemiology of an obligate biotroph. Mol. Plant Pathol. 13, 1-16. doi: 10.1111/j.1364-3703.2011. 00728.x

Gao, J., Wang, G., Ma, S., Xie, X., Wu, X., Zhang, X., et al. (2015). CRISPR/Cas9mediated targeted mutagenesis in Nicotiana tabacum. Plant Mol. Biol. 87, 99-110. doi: 10.1007/s11103-014-0263-0

Hendel, A., Fine, E. J., Bao, G., and Porteus, M. H. (2015). Quantifying on- and offtarget genome editing. Trends Biotechnol. 33, 132-140. doi: 10.1016/j.tibtech. 2014.12.001

Hsu, P. D., Scott, D. A., Weinstein, J. A., Ran, F. A., Konermann, S., Agarwala, V., et al. (2013). DNA targeting specificity of RNA-guided Cas9 nucleases. Nat. Biotechnol. 31, 827-832. doi: 10.1038/nbt.2647

Jiang, W., Zhou, H., Bi, H., Fromm, M., Yang, B., and Weeks, D. P. (2013). Demonstration of CRISPR/Cas9/sgRNA-mediated targeted gene modification in Arabidopsis, tobacco, sorghum and rice. Nucleic Acids Res. 41:e188. doi: $10.1093 /$ nar/gkt780

Jones, H. D. (2015). Regulatory uncertainty over genome editing. Nat. Plants 1:14011. doi: 10.1038/nplants.2014.11

Kanchiswamy, C. N. (2016). DNA-free genome editing methods for targeted crop improvement. Plant Cell Rep. 35, 1469-1474. doi: 10.1007/s00299-016-1982-2

Kanchiswamy, C. N., Maffei, M., Malnoy, M., Velasco, R., and Kim, J. S. (2016). Fine-tuning next-generation genome editing tools. Trends Biotechnol. 34, 562-574. doi: 10.1016/j.tibtech.2016.03.007

Kanchiswamy, C. N., Sargent, D. J., Velasco, R., Maffei, M. E., and Malnoy, M. (2015). Looking forward to genetically edited fruit crops. Trends Biotechnol. 33, 62-64. doi: 10.1016/j.tibtech.2014.07.003

Kim, S., Kim, D., Cho, S. W., Kim, J., and Kim, J. S. (2014). Highly efficient RNA-guided genome editing in human cells via delivery of purified Cas9 ribonucleoproteins. Genome Res. 24, 1012-1019. doi: 10.1101/gr.171322.113

Koo, T., Lee, J., and Kim, J. S. (2015). Measuring and reducing off-target activities of programmable nucleases including CRISPR-Cas9. Mol. Cells 38, 475-481. doi: $10.14348 /$ molcells. 2015.0103

Ledford, H. (2013). US regulation misses some GM crops. Nature 500, 389-390. doi: $10.1038 / 500389$ a

Lee, J. S., Kwak, S. J., Kim, J., Kim, A. K., Noh, H. M., Kim, J. S., et al. (2014). RNA-guided genome editing in Drosophila with the purified Cas9 protein. G3 (Bethesda) 4, 1291-1295. doi: 10.1534/g3.114.012179

Lei, R., Qiao, W., Hu, F., Jiang, H., and Zhu, S. (2015). A simple and effective method to encapsulate tobacco mesophyll protoplasts to maintain cell viability. MethodsX 2, 24-32. doi: 10.1016/j.mex.2014.11.004
Li, J. F., Norville, J. E., Aach, J., McCormack, M., Zhang, D., Bush, J., et al. (2013). Multiplex and homologous recombination-mediated genome editing in Arabidopsis and Nicotiana benthamiana using guide RNA and Cas9. Nat. Biotechnol. 31, 688-691. doi: 10.1038/nbt.2654

Liu, J., Gaj, T., Yang, Y., Wang, N., Shui, S., Kim, S., et al. (2015). Efficient delivery of nuclease proteins for genome editing in human stem cells and primary cells. Nat. Protoc. 10, 1842-1859. doi: 10.1038/nprot.2015.117

Mali, P., Aach, J., Stranges, P. B., Esvelt, K. M., Moosburner, M., Kosuri, S., et al. (2013). CAS9 transcriptional activators for target specificity screening and paired nickases for cooperative genome engineering. Nat. Biotechnol. 31, 833-838. doi: 10.1038/nbt.2675

Meng, X., Bonasera, J. M., Kim, J. F., Nissinen, R. M., and Beer, S. V. (2006). Apple proteins that interact with DspA/E, a pathogenicity effector of Erwinia amylovora, the fire blight pathogen. Mol. Plant Microbe Interact. 19, 53-61. doi: 10.1094/MPMI- 19-0053

Nishitani, C., Hirai, N., Komori, S., Wada, M., Okada, K., Osakabe, K., et al. (2016). Efficient genome editing in apple using a CRISPR/Cas9 system. Sci. Rep. 6:31481. doi: 10.1038/srep31481

Patat-Ochatt, E. M. (1994). "Regeneration of plants from protoplasts of Malus Xdomestica Borkh. (Apple)," in Plant Protoplasts and Genetic and Engineering $V$, ed. Y. P. S. Bajaj (Berlin: Springer), 83-101. doi: 10.1007/978-3-66209366-5_7

Patat-Ochatt, E. M., Boccon-Gibod, J., Duron, M., and Ochatt, S. J. (1993). Organogenesis of stem and leaf protoplasts of a haploid golden delicious apple clone (Malus Xdomestica Borkh.). Plant Cell Rep. 12, 118-120. doi: 10.1007/ BF00241946

Pessina, S., Lenzi, L., Perazzolli, M., Campa, M., Dalla Costa, L., Urso, S., et al. (2016). Knockdown of MLO genes reduces susceptibility to powdery mildew in grapevine. Hortic. Res. 3:16016. doi: 10.1038/hortres.2016.16

Quail, M. A., Smith, M., Coupland, P., Otto, T. D., Harris, S. R., Connor, T. R., et al. (2012). A tale of three next generation sequencing platforms: comparison of Ion Torrent, Pacific Biosciences and Illumina MiSeq sequencers. BMC Genomics 13:341. doi: 10.1186/1471-2164-13-341

Ran, F. A., Hsu, P. D., Lin, C. Y., Gootenberg, J. S., Konermann, S., Trevino, A. E., et al. (2013). Double nicking by RNA-guided CRISPR Cas9 for enhanced genome editing specificity. Cell 154, 1380-1389. doi: 10.1016/j.cell.2013.08.021

Ren, C., Liu, X., Zhang, Z., Wang, Y., Duan, W., Li, S., et al. (2016). CRISPR/Cas9mediated efficient targeted mutagenesis in Chardonnay (Vitis vinifera L.). Sci. Rep. 6:32289. doi: 10.1038/srep32289

Reustle, G., Harst, M., and Alleweldt, G. (1995). Plant regeneration of grapevine (Vitis sp.) protoplasts isolated from embryogenic tissue. Plant Cell Rep. 15, 238-241. doi: 10.1007/BF00193727

Saito, A., and Suzuki, M. (1999). Plant regeneration from meristem-derived callus protoplasts of apple (Malus3domestica cv. 'Fuji'). Plant Cell Rep. 18, 549-553. doi: 10.1007/s002990050620

Shan, Q., Wang, Y., Li, J., Zhang, Y., Chen, K., Liang, Z., et al. (2013). Targeted genome modification of crop plants using a CRISPR-Cas system. Nat. Biotechnol. 31, 686-688. doi: 10.1038/nbt.2650

Singh, O. V., Ghai, S., Paul, D., and Jain, R. K. (2006). Genetically modified crops: success, safety assessment, and public concern. Appl. Microbiol. Biotechnol. 71, 598-607. doi: 10.1007/s00253-006-0449-8

Song, G., Jia, M., Chen, K., Kong, X., Khattak, B., Xie, C., et al. (2016). CRISPR/Cas9: a powerful tool for crop genome editing. Crop J. 4, 75-82. doi: 10.1016/j.cj.2015.12.002

Sprink, T., Eriksson, D., Schiemann, J., and Hartung, F. (2016). Regulatory hurdles for genome editing: process- vs. product-based approaches in different regulatory contexts. Plant Cell Rep. 35, 1493-1506. doi: 10.1007/s00299-0161990-2

Subburaj, S., Chung, S. J., Lee, C., Ryu, S. M., Kim, D. H., Kim, J. S., et al. (2016). Site-directed mutagenesis in Petunia $x$ hybrida protoplast system using direct delivery of purified recombinant Cas9 ribonucleoproteins. Plant Cell Rep. 35, 1535-1544. doi: 10.1007/s00299-016-1937-7

Sung, Y. H., Kim, J. M., Kim, H. T., Lee, J., Jeon, J., Jin, Y., et al. (2014). Highly efficient gene knockout in mice and zebrafish with RNA-guided endonucleases. Genome Res. 24, 125-131. doi: 10.1101/gr.163394.113

Tan, E. P., Li, Y., Velasco-Herrera Mdel, C., Yusa, K., and Bradley, A. (2015). Offtarget assessment of CRISPR-Cas9 guiding RNAs in human iPS and mouse ES cells. Genesis 53, 225-236. doi: 10.1002/dvg.22835 
Waltz, E. (2012). Tiptoeing around transgenics. Nat. Biotechnol. 30, 215-217. doi: $10.1038 /$ nbt. 2143

Wang, Y., Cheng, X., Shan, Q., Zhang, Y., Liu, J., Gao, C., et al. (2014). Simultaneous editing of three homoeoalleles in hexaploid bread wheat confers heritable resistance to powdery mildew. Nat. Biotechnol. 32, 947-951. doi: 10. 1038/nbt.2969

Woo, J. W., Kim, J., Kwon, S. I., Corvalan, C., Cho, S. W., Kim, H., et al. (2015). DNA-free genome editing in plants with preassembled CRISPR-Cas9 ribonucleoproteins. Nat. Biotechnol. 33, 1162-1164. doi: 10.1038/nbt.3389

Xie, K., and Yang, Y. (2013). RNA-guided genome editing in plants using a CRISPR-Cas system. Mol. Plant 6, 1975-1983. doi: 10.1093/mp/sst119

Zhang, X. H., Tee, L. Y., Wang, X. G., Huang, Q. S., and Yang, S. H. (2015). Offtarget Effects in CRISPR/Cas9-mediated Genome Engineering. Mol. Therapy Nucleic Acids 4:e264. doi: 10.1038/mtna.2015.37

Zhang, Y., Liang, Z., Zong, Y., Wang, Y., Liu, J., Chen, K., et al. (2016). Efficient and transgene-free genome editing in wheat through transient expression of CRISPR/Cas9 DNA or RNA. Nat. Commun. 7:12617. doi: 10. 1038/ncomms 12617

Zhao, F.-L., Li, Y.-J., Hu, Y., Gao, Y.-R., Zang, X.-W., Ding, Q., et al. (2016). A highly efficient grapevine mesophyll protoplast system for transient gene expression and the study of disease resistance proteins. Plant Cell Tissue Organ Culture 125, 43-57. doi: 10.1007/s11240-015-0928-7

Zhu, Y.-M., Hoshino, Y., Nakano, M., Takahashi, E., and Mii, M. (1997). Highly efficient system of plant regeneration from protoplasts of grapevine (Vitis vinifera L.) through somatic embryogenesis by using embryogenic callus culture and activated charcoal. Plant Sci. 123, 151-157. doi: 10.1016/S0168-9452(96) 04557-8

Conflict of Interest Statement: The authors declare that the research was conducted in the absence of any commercial or financial relationships that could be construed as a potential conflict of interest.

Copyright (c) 2016 Malnoy, Viola, Jung, Koo, Kim, Kim, Velasco and Nagamangala Kanchiswamy. This is an open-access article distributed under the terms of the Creative Commons Attribution License (CC BY). The use, distribution or reproduction in other forums is permitted, provided the original author(s) or licensor are credited and that the original publication in this journal is cited, in accordance with accepted academic practice. No use, distribution or reproduction is permitted which does not comply with these terms. 